\section{A) Check for updates}

Cite this: Polym. Chem., 2020, 11 7410

\title{
Poly(vinyl acetate-co-ethylene) particles prepared by surfactant-free emulsion polymerization in the presence of a hydrophilic RAFT/MADIX macromolecular chain transfer agent $\uparrow$
}

\author{
James Delorme, (D) a Olivier Boyron, (D) a Pierre-Yves Dugas, (D) a \\ Pierre-Emmanuel Dufils, (DD ${ }^{\mathrm{b}}$ D. James Wilson, (D) ${ }^{\mathrm{b}}$ Vincent Monteil, (D) ${ }^{\mathrm{a}}$ \\ Franck D'Agosto (D) *a and Muriel Lansalot (D)*a
}

\begin{abstract}
Poly(acrylamide-co-acrylic acid) (P(AAm-Co-AA)-X) was prepared by RAFT/MADIX and used as a hydrophilic macromolecular chain transfer agent (macroCTA) in the aqueous emulsion copolymerization of vinyl acetate (VAc) and ethylene. Stable latexes were obtained over a broad range of conditions with macroCTA contents ranging from 1 to $65 \mathrm{wt} \%$ (compared to the initial amount of VAc) and ethylene pressure from 10 to 100 bar. The different systems investigated generated latexes incorporating amorphous to semi-crystalline poly(vinyl acetate-co-ethylene) (P(VAc-Co-E)) chains using macroCTA content as low as $1 \mathrm{wt} \%$ in the absence of additional surfactant. The particle nucleation mechanism was investigated with the help of kinetic studies using cryogenic transmission electronic microscopy (cryoTEM) and was consistent with the concepts underlying polymerization-induced self-assembly (PISA). High solids content latexes were finally targeted with a formulation more in line with industrial constraints $(0.4 \mathrm{wt} \%$ macroCTA, 35 bar ethylene pressure, semi-batch conditions). A stable P(VAc-CO-E) latex was produced exhibiting a solids content of $38 \mathrm{wt} \%$. This work provides an easy access to a full range of alternative stabilization modes for P(VAc-Co-E) latexes and potentially to new VAE and EVA products.
\end{abstract}

Received 7th September 2020 Accepted 16th October 2020

DOI: 10.1039/d0py01266a

rsc.li/polymers
co-E)), also called VAE or EVA, respectively, can achieve completely amorphous to semi-crystalline properties. EVAs find applications in fuel additives, wire and cable insulation or foams, while VAEs are used for adhesive, paint and coating applications. ${ }^{2-5}$ In the case of VAEs, which are the main topic of this communication, ethylene actually acts as a plasticizing comonomer for PVAc, to counterbalance the rigid nature of the latter and bring more flexibility to the polymer backbone. ${ }^{1}$ Industrially, VAEs are mostly produced by aqueous emulsion polymerization at temperatures below $100{ }^{\circ} \mathrm{C}$ between 20 and 120 bar of ethylene pressure (mainly up to 30 bar). ${ }^{6}$ Whereas the patent literature on $\mathrm{VAE}$ synthesis is quite large, the number of papers available in the open literature is comparatively rather limited. This is likely due to the fact that special equipment is required to work with ethylene (high pressure reactor). In addition, as a gas, ethylene induces more complexity in the systems in terms of monomer partitioning and diffusion. The most extensive study was conducted by Scott et al. ${ }^{3,7-10}$ who have screened in detail the impact of different parameters on semi-batch emulsion copolymerization of ethylene and vinyl acetate, such as the type and amount of the initiating system, of the buffer, and of the emulsifier. The addition of a co-solvent and the VAc feed rate were also considered, as 
well as the agitation and mixing phenomena and the reactor design. Experiments were mostly performed at low temperatures (20 and $40{ }^{\circ} \mathrm{C}$ ) and pressures (15 to 35 bar) as the authors were aiming at increasing the ethylene content under mild conditions. This allowed the formation of copolymers containing up to $34 \mathrm{wt} \%$ of ethylene units. The large number of these tunable parameters and their interactions demonstrate the complexity of VAE syntheses. In this process, the surfactant is an important ingredient in the recipe since, after the composition of the final VAE itself, it defines to a large extent the final properties of the targeted product. ${ }^{11}$ Different types of surfactants have thus been investigated to produce VAE latexes. These include conventional anionic surfactants, ${ }^{3,7,12-15}$ mixtures of anionic and nonionic surfactants, ${ }^{7}$ protective colloids such as hydroxyethyl cellulose ${ }^{7}$ or poly(vinyl alcohol) $(\mathrm{PVOH})^{9,11,16,17}$ or combinations of those. ${ }^{9,18,19}$ PEG-based macromolecules have also been investigated. ${ }^{11}$

Among the different strategies employed, the use of hydrophilic PVOH as protective colloid is quite widespread. Indeed, resulting from partial hydrolysis of preformed PVAc, $\mathrm{PVOH}$ offers multiple stabilization possibilities depending on its VAc content and its microstructure, that can be blocky depending on the PVAc hydrolysis conditions, ${ }^{20-22}$ and consequently leads to various VAE products.

When $\mathrm{PVOH}$ is used for VAc emulsion polymerization, it somehow acts as a reactive stabilizer due to chain transfer reactions taking place in water along $\mathrm{PVOH}$ chains, followed by reinitiation of VAc polymerization..$^{23-26}$ To the best of our knowledge, the occurrence of such reactions in the case of emulsion copolymerization of vinyl acetate and ethylene has been only briefly mentioned by Reynolds, ${ }^{1}$ but never evidenced. However, considering the similar reactivity of these two monomers (reactivity ratios, $r_{\mathrm{VAc}}$ and $r_{\mathrm{E}}$, are both close to one, with a slight pressure dependence of $r_{\mathrm{E}}{ }^{27-31}$ ), and the fact that VAc is significantly more water-soluble $\left(26 \mathrm{~g} \mathrm{~L} \mathrm{~L}^{-1}\right.$ at $\left.50{ }^{\circ} \mathrm{C}^{32}\right)$ than ethylene $\left(0.3 \mathrm{~g} \mathrm{~L}^{-1}\right.$ at 4.5 bar to $4.6 \mathrm{~g} \mathrm{~L}^{-1}$ at 111 bar, at $75^{\circ} \mathrm{C}^{33}$ ), one can safely assume that similar transfer reactions happen during VAE synthesis and that particle stabilization is most probably ensured via grafting reactions occurring along the PVOH backbone. ${ }^{1}$

Reversible-deactivation radical polymerization (RDRP) techniques may advantageously be used in emulsion polymerization to form surfactant-free latexes. ${ }^{34,35}$ This approach is indeed part of the so-called polymerization-induced self-assembly (PISA) strategy, ${ }^{34-37}$ which takes advantage of the chain-end reactivity of solvophilic macromolecules obtained by RDRP for the polymerization of solvophobic monomers. Hydrophilic chains can thus be extended with hydrophobic monomers directly in water. The amphiphilic block copolymers formed in situ are not only excellent stabilizers for the particles produced simultaneously by emulsion polymerization, but also provide an interesting tool to tailor the particle surface through the composition of the hydrophilic segment.

We successfully undertook several studies based on this concept employing hydrophilic polymer chains obtained by reversible addition-fragmentation chain transfer (RAFT) and

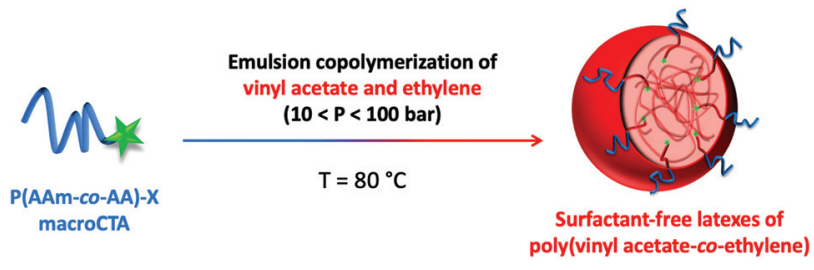

Scheme 1 Preparation of poly(vinyl acetate-co-ethylene) particles by emulsion polymerization using $\mathrm{P}(\mathrm{AAm}-\mathrm{co}-\mathrm{AA})-\mathrm{X}$ as macroCTA.

macromolecular design by interchange of xanthates (MADIX) in order to produce industrially relevant surfactant-free formulation for the production of film forming latex such as poly (meth)acrylics, ${ }^{38-41}$ poly(vinylidene fluoride) ${ }^{42}$ and poly(vinylidene chloride). ${ }^{43-45}$

In the present paper, we apply this strategy for the first time to the emulsion copolymerization of ethylene and vinyl acetate for the production of VAE, building on our recent works on the polymerization of ethylene by free radical polymerization in water under mild conditions (i.e., temperature $<90{ }^{\circ} \mathrm{C}$ and ethylene pressure $<250$ bar $),{ }^{46-48}$ and on PVAc $^{49,50}$ and polyethylene $(\mathrm{PE})^{51}$ particle synthesis mediated by macromolecular chain transfer agents (macroCTAs). The reactivity of these two monomers restricts the choice of potential macroCTAs to hydrophilic polymer chains carrying dithiocarbonate or dithiocarbamate end groups. Here, a poly(acrylamide-co-acrylic acid) (P(AAm-co-AA)-X) containing an equimolar ratio of AA and AAm was prepared by RAFT/MADIX and employed in emulsion polymerization as hydrophilic macroCTA (Scheme 1). The ethylene pressure and the macroCTA content were varied to first validate the strategy and then identify the potential of the system. Analysis of the obtained latexes was performed to characterize the particles by dynamic light scattering (DLS) and cryogenic transmission electronic microscopy (cryoTEM), but also the copolymer chains by differential scanning calorimetry (DSC), thermogravimetry (TGA), infrared (IR) and nuclear magnetic resonance (NMR) spectroscopy. Eventually, conditions were identified to isolate stable VAE latexes under industrially relevant experimental conditions and the process (batch or semi-batch) was adjusted to achieve high solids content. To the best of our knowledge, this is the first time that reactive macromolecules obtained by RDRP (RAFT/MADIX here) are used to form VAE latexes.

\section{Experimental}

\section{Materials}

Acrylic acid (AA, Aldrich, 99.8\%), acrylamide (AAm, SNF, $50 \mathrm{wt} \%$ solution), ammonium persulfate (APS, Aldrich, >98\%), ethylene (E, 99.95\%, Air Liquide), Rhodixan A1 (Solvay, 95\%), hydroxymethane sulfonic acid sodium salt dihydrate (NaFS, Aldrich, >98\%), sodium persulfate (NaPS, 98+\%, Aldrich) and ethanol (VWR, 96\%) were used as received. Vinyl acetate (VAc, $99+\%$, Aldrich) was purified by removing the inhibitor by fil- 
tration with aluminum oxide. Water was deionized before use (Purelab ClassicUV, Elga LabWater).

\section{Synthesis of poly(acrylamide-co-acrylic acid) (P(AAm-co-AA)-X macroCTA}

In a typical procedure, water (58 g), ethanol (70 g), Rhodixan A1 (25 g), AA (4.84 g) and AAm (14.35 g, 50 wt\% solution) were introduced in a glass reactor, equipped with a mechanical stirrer and a condenser. After deoxygenation by nitrogen bubbling, the mixture was heated to $40{ }^{\circ} \mathrm{C}$. Then, aqueous solutions of APS (13.74 g, $16 \mathrm{wt} \%$ ), and NaFS (4.87 g, $1 \mathrm{wt} \%$ ) were introduced shot-wise. At the same time a solution of AA (236.9 g)/AAm (703.35 g, $50 \mathrm{wt} \%$ ) and NaFS (34.66 g, $1.25 \mathrm{wt} \%$ ) were introduced in the reactor for 240 minutes and 695 minutes respectively. After 300 minutes, the mixture was heated to $60{ }^{\circ} \mathrm{C}$ for 300 minutes and then cooled down to room temperature. Conversion of both monomers was complete (as evidenced by HLPC - data not shown), and the final polymer (Scheme 2) was obtained as a $36 \mathrm{wt} \%$ aqueous solu-

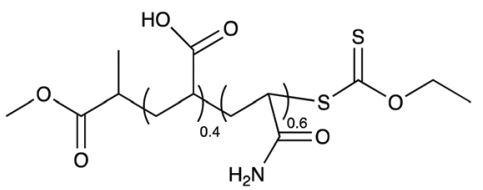

Scheme 2 Structure of P(AAm-Co-AA)-X macroCTA. tion. The dried polymer was characterized by aqueous size exclusion chromatography $\left(M_{\mathrm{n}} \approx 5300 \mathrm{~g} \mathrm{~mol}^{-1}\right.$ and $\left.\boxplus=1.3\right)$.

\section{Batch emulsion copolymerizations of vinyl acetate and ethylene}

Caution: Polymerizations involve high pressures and explosive gas.

Copolymerizations (Table 1) were performed in a $160 \mathrm{~mL}$ stainless steel autoclave (from Parr Instrument Co.) equipped with safety valves and a stirrer. An intermediate $1.5 \mathrm{~L}$ tank filled with ethylene was used to charge the reactor. The tank was cooled down to $-20^{\circ} \mathrm{C}$ to liquefy ethylene at 35 bar. Then the intermediate tank was isolated and heated to reach up to 300 bar of ethylene pressure. The initiator NaPS, macroCTA solution, VAc and water were introduced in a Schlenk tube. The volume of this mixture was always equal to $50 \mathrm{~mL}$. Then the mixture was deoxygenated by argon bubbling for $30 \mathrm{~min}$ and introduced into the reactor through a cannula. The reactor was heated up to $77^{\circ} \mathrm{C}$ beforehand and freed from oxygen by successive vacuum-argon cycles. Afterwards, ethylene was introduced until the desired pressure was reached, which marked the beginning of the polymerization. It is important to note that for all the polymerizations, the ethylene pressure value refers to the pressure set at the beginning of the polymerization. Pressure was not maintained constant during the polymerization, which induced depletion of ethylene from the reaction medium over time. The stirring speed was always set to $400 \mathrm{rpm}$. After the desired polymerization time, the reac-

Table 1 Batch aqueous emulsion copolymerizations of VAc and ethylene mediated by $\mathrm{P}(\mathrm{AAm}-\mathrm{CO}-\mathrm{AA})-\mathrm{X}$

\begin{tabular}{|c|c|c|c|c|c|c|c|c|c|c|c|c|c|}
\hline Latex & $\begin{array}{l}\operatorname{macroCTA}^{a} \\
(\text { wt } \%)\end{array}$ & $\begin{array}{l}P \\
\text { (bar) }\end{array}$ & $\begin{array}{l}{[\mathrm{VAc}]} \\
\left(\mathrm{mol} \mathrm{L}^{-1}\right)\end{array}$ & $\begin{array}{l}\text { Time } \\
\text { (min) }\end{array}$ & $\begin{array}{l}\mathrm{SC}^{b} \\
(\%)\end{array}$ & $\begin{array}{l}\mathrm{PC}^{b} \\
(\%)\end{array}$ & $\begin{array}{l}Z_{\text {ave }}{ }^{c} \\
(\mathrm{~nm})\end{array}$ & $\mathrm{PdI}^{c}$ & $\begin{array}{l}\text { VAc }^{d} \\
(\mathrm{wt} \%)\end{array}$ & $\begin{array}{l}\operatorname{VAc}^{e} \\
(\mathrm{~mol} \%)\end{array}$ & $\begin{array}{l}X_{\mathrm{VAc}}^{f} \\
(\%)\end{array}$ & $\begin{array}{l}T_{\mathrm{g}}^{g} \\
\left({ }^{\circ} \mathrm{C}\right)\end{array}$ & $\begin{array}{l}X_{\mathrm{c}}^{h} \\
(\%)\end{array}$ \\
\hline $\mathrm{L} 1^{i}$ & 1 & 0 & 1.09 & 240 & 8.0 & 7.7 & 150 & 0.03 & 100 & 100 & 79 & 42.8 & - \\
\hline L2 & 1 & 10 & 1.09 & 240 & 9.4 & 9.1 & 145 & 0.02 & 88.7 & 77.1 & 89 & 30.8 & - \\
\hline L3 & 1 & 35 & 1.09 & 240 & 9.7 & 9.3 & 158 & 0.02 & 80.6 & 57.5 & 80 & 7.7 & - \\
\hline $\mathrm{L} 4$ & 1 & 50 & 1.09 & 240 & 11.4 & 11.2 & 148 & 0.02 & 70.0 & 43.2 & 83 & -12.0 & 1.2 \\
\hline L5 & 1 & 100 & 1.09 & 240 & 13.9 & 13.7 & 165 & 0.03 & 41.7 & 19.0 & 61 & -35.7 & 9.1 \\
\hline L6 & 0 & 35 & 1.09 & 60 & 5.8 & 5.7 & 505 & 0.10 & 85.0 & 64.9 & 50 & 10.3 & - \\
\hline $\mathrm{L} 3^{* j}$ & 1 & 35 & 1.09 & 240 & 8.7 & 8.4 & 564 & 0.13 & 74.5 & 48.9 & 67 & 4.0 & - \\
\hline L21 & 10 & 50 & 1.09 & 5 & 1.3 & 0.2 & - & - & - & - & - & - & - \\
\hline L22 & 10 & 50 & 1.09 & 10 & 3.3 & 2.2 & 55 & 0.3 & - & - & - & 8.2 & - \\
\hline L23 & 10 & 50 & 1.09 & 20 & 8.1 & 7.0 & 59 & 0.1 & 79.5 & 55.8 & 58 & 8.4 & - \\
\hline L10 & 10 & 50 & 1.09 & 240 & 12.5 & 11.4 & 100 & 0.2 & 54.4 & 28.3 & 69 & -33.0 & 6.6 \\
\hline L24 & 1 & 35 & 1.09 & 15 & 7.4 & 7.1 & 170 & 0.16 & 82.0 & 59.7 & 61 & 18.5 & - \\
\hline L25 & 1 & 35 & 1.09 & 30 & 8.5 & 8.3 & 158 & 0.02 & 89.5 & 72.5 & 78 & 14.1 & - \\
\hline L26 & 1 & 35 & 1.09 & 60 & 8.4 & 8.2 & 161 & 0.03 & 84.7 & 63.1 & 72 & 11.5 & - \\
\hline L27 & 1 & 35 & 2.18 & 60 & 19.0 & 18.6 & 165 & 0.04 & 87.9 & 70.5 & 88 & 19.4 & - \\
\hline L28 & 1 & 35 & 3.25 & 60 & 29.3 & 28.8 & 184 & 0.02 & 86.0 & 66.6 & 90 & 19.1 & - \\
\hline $\mathrm{L} 29^{k}$ & 1 & 35 & 4.32 & 60 & 36.4 & 35.7 & 220 & 0.08 & 86.0 & 66.6 & 82 & 16.4 & - \\
\hline
\end{tabular}

For all experiments, $T=77^{\circ} \mathrm{C}$. ${ }^{a}$ With respect to VAc amount. ${ }^{b}$ Solid content (SC) and polymer content (PC), with PC = SC - amount of non-volatile species (in \%). ${ }^{C}$ Determined by DLS. ${ }^{d}$ Weight content of VAc units in formed P(VAc-co-E) determined by averaging the values from the relevant analyses (see ESI $\dagger$ ). ${ }^{e}$ Molar content of VAc units in formed $\mathrm{P}(\mathrm{VAc}-\mathrm{co}-\mathrm{E})$ ) determined by averaging the values from the relevant analyses (see ESI $\dagger$ ). ${ }^{f}$ VAc conversion calculated from eqn (1). ${ }^{g}$ Determined by DSC. ${ }^{h}$ Degree of crystallinity $\left(X_{\mathrm{c}}\right)$ calculated from eqn $(2) .{ }^{i}$ The latex was not stable after $24 \mathrm{~h} .{ }^{j}$ Experiment run with $\mathrm{P}(\mathrm{AAm}-c o-\mathrm{AA})$, after removal of the xanthate chain end in $\mathrm{P}(\mathrm{AAm}-c o-\mathrm{AA})-\mathrm{X}$ via peracetic acid treatment. ${ }^{k} \mathrm{~A}$ large proportion of aggregates was present at the end of the polymerization $(14.9 \mathrm{wt} \%)$. 
tor's jacket was cooled down by water. The reactor was then slowly degassed until reaching atmospheric pressure to collect the latex.

When kinetic studies were undertaken an experiment was carried out for each investigated time as no withdrawal of samples was technically possible during the polymerization.

\section{Semi-batch emulsion copolymerizations of vinyl acetate and ethylene}

For this process (Table 2), the reactor was set up the same way as for the batch process, but the preparation of the reaction mixture differed. In a first Schlenk tube were introduced a desired amount of initiator, macroCTA solution, water and VAc $\left(m_{\mathrm{VAc}}\right)$. The volume in this Schlenk tube was always equal to $50 \mathrm{~mL}$. The solution was then degassed under argon for $30 \mathrm{~min}$. In a second Schlenk tube was introduced a desired amount of VAc $\left(2 m_{\mathrm{VAc}}\right.$ for L30 and $3 m_{\mathrm{VAc}}$ for L31). This medium was also degassed under argon for $30 \mathrm{~min}$. The polymerization was launched using the same protocol as for the batch process. Then, every hour, $m_{\mathrm{VAc}}$ was injected as a single shot into the reactor using a HPLC pump (flow rate $=10 \mathrm{~mL}$ $\min ^{-1}$ ). Note that the ability of the pump to precisely deliver the corresponding quantity in the pressurized reactor has been checked. There were 2 and 3 injections for L30 and L31, respectively, during the polymerization. After the last addition, the polymerization was allowed to proceed for one more hour, setting the total reaction time to 3 and 4 hours, respectively. The polymerization was stopped as described for the batch process.

\section{Characterization}

Aqueous size exclusion chromatography (ASEC). SEC analyses were performed on $\mathrm{P}(\mathrm{AAm}-\mathrm{co}-\mathrm{AA})-\mathrm{X}$ macroCTA using analytical HPLC system (1100 series Instruments) including a differential refractive index (RI) detector (1100 series, Agilent) and a multi-angle laser light scattering (MALLS) detector (Mini Dawn TREOS, Wyatt). An aqueous solution ( $\mathrm{NaCl} 100 \mathrm{mM}$, $\mathrm{NaH}_{2} \mathrm{PO}_{4} 25 \mathrm{mM}, \mathrm{Na}_{2} \mathrm{HPO}_{4} 25 \mathrm{mM}$ ) buffered at $\mathrm{pH} 7$ was used as the mobile phase at a flow rate of $1 \mathrm{~mL} \mathrm{~min}^{-1}$ at $20^{\circ} \mathrm{C}$. All samples were injected at a concentration of $0.5 \mathrm{wt} \%$ after filtration through a $0.45 \mu \mathrm{m}$ PVDF membrane. The separation was carried out on a guard column followed by three analytical columns (Varian Aquagel $\mathrm{OH}$ mixed H, $8 \mu \mathrm{m}, 300 \mathrm{~mm}$ ). The absolute average molar masses (number-average molar mass, $M_{\mathrm{n}}$ and weight-average molar mass, $M_{\mathrm{w}}$ ) and the dispersity, $Ð=M_{\mathrm{w}} / M_{\mathrm{n}}$, were calculated from the MALLS detector signal using a $\mathrm{d} n / \mathrm{d} C$ value of $0.18 \mathrm{~mL} \mathrm{~g}^{-1}$.
Gravimetric analysis. A known amount of latex ( $\left.m_{\text {latex }}\right)$ was dried at $60^{\circ} \mathrm{C}$ for 12 hours to evaporate volatile compounds, allowing determination of the solids content (SC). Subtraction of the non-volatile species (i.e. macroCTA and initiator) gave access to the polymer content (PC, i.e. $\mathrm{P}(\mathrm{VAc}-\mathrm{Co}-\mathrm{E})$ only). The $\mathrm{PC}$, the knowledge of the composition of the copolymers formed (wt $\%$ VAc and $\mathrm{wt} \%$ ethylene) and the amount of VAc introduced ( $m_{\mathrm{VAc}}$ introduced $)$ allow to calculate the VAc conversion $\left(X_{\mathrm{VAc}}\right)$ as follows:

$$
X_{\mathrm{VAc}}(\%)=\left(\frac{P C \times m_{\text {latex }} \times \mathrm{wt} \% \mathrm{VAc}}{m_{\mathrm{VAc} \text { introduced }}}\right) \times 100
$$

Dynamic light scattering (DLS). The intensity-weighted average diameter (or $Z$-average diameter), $Z_{\text {ave }}$, of the particles and the dispersity factor (PdI) were measured at $25{ }^{\circ} \mathrm{C}$ using a Zetasizer Nano Series (Nano ZS) from Malvern Instruments. Before measurements, the latex sample was diluted with deionized water. The mean particle diameter was averaged over three consecutive runs. The data were collected at $173^{\circ}$ scattering angle using the fully automatic mode of the Zetasizer system and fitted with the cumulants analysis.

Cryogenic-transmission electron microscopy (cryo-TEM). In order to preserve particle shape, latexes were observed in their natural hydrated environment using cryo-TEM. Diluted suspensions were dropped onto 300 mesh holey carbon films (Quantifoil R2/1) and quench-frozen in liquid ethane using a cryo-plunge workstation (made at Laboratoire de Physique des Solides-LPS, Orsay, France). The grids were then mounted on a precooled Gatan 626 specimen holder, transferred in the Philips CM120 transmission electron microscope (Centre Technologique des Microstructures (CT $\mu)$, platform of the Université Claude Bernard Lyon 1, Villeurbanne, France) operating at an accelerating voltage of $120 \mathrm{kV}$.

Differential scanning calorimetry (DSC). Differential scanning calorimetry (DSC) was performed on a Mettler Toledo DSC3+ at a heating rate of $10{ }^{\circ} \mathrm{C} \mathrm{min}^{-1}$. Two successive heating and cooling steps of the samples were performed. Glass transition $\left(T_{\mathrm{g}}\right)$ values were obtained during the second heating cycle. The $T_{\mathrm{g}}$ values were used to calculate the compositions of the copolymers (see ESI $\dagger$ ). In some cases, the degree of crystallinity of $\mathrm{P}(\mathrm{VAc}-\mathrm{Co}-\mathrm{E})$ was calculated from the second heating curve using the following equation:

$$
X_{\mathrm{c}}(\%)=\left(\frac{\Delta H_{\mathrm{m}}}{\Delta H_{\mathrm{m}}^{\circ}}\right) \times 100
$$

with $\Delta H_{\mathrm{m}}^{\circ}=293 \mathrm{Jg}^{-1}$ as standard enthalpy of polyethylene.

Table 2 Semi-batch aqueous emulsion copolymerizations of VAc and ethylene at constant pressure of ethylene (35 bar)

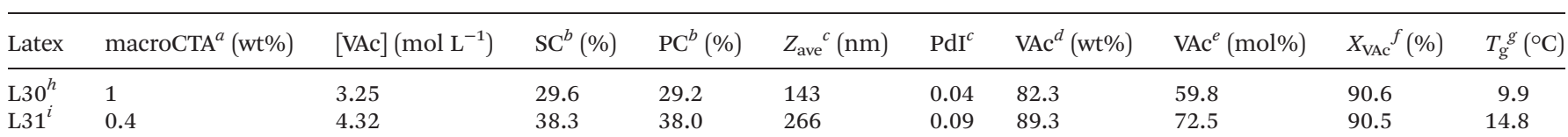

For all experiments, $T=77^{\circ} \mathrm{C}$. ${ }^{a}$ With respect the VAc amount. ${ }^{b}$ Solid content (SC) and polymer content (PC), with PC = SC - amount of non-volatile species (in \%). ${ }^{c}$ Determined by DLS. ${ }^{d}$ Weight content of VAc units in formed P(VAc-co-E) determined by averaging the values from the relevant analyses (see ESI $\dagger$ ). ${ }^{e}$ Molar content of VAc units in formed $\mathrm{P}(\mathrm{VAc}-\mathrm{co}$-E) determined by averaging the values from the relevant analyses (see ESI $\dagger$ ). ${ }^{f}$ VAc conversion calculated from eqn (1). ${ }^{g}$ Determined by DSC. ${ }^{h}$ VAc was added in 2 shots. ${ }^{i}$ VAc was added in 3 shots. 
Thermogravimetric analysis (TGA). The analysis was performed using a thermogravimetric analyzer TGA/DSC 1 from Mettler Toledo. Dry VAE samples and dry macroCTA samples were submitted to heating from 25 to $600{ }^{\circ} \mathrm{C}$ at a heating rate of $10{ }^{\circ} \mathrm{C} \mathrm{min}^{-1}$ under $\mathrm{N}_{2}$ flow $\left(30 \mathrm{~mL} \mathrm{~min}^{-1}\right.$ ). The mass loss of acetic acid from the thermogram data was used to calculate the compositions of the copolymers (see ESI $\dagger$ ).

Attenuated total reflectance-Fourier transform infrared spectroscopy (ATR-FTIR). The analyses were performed at room temperature on a Nicolet IS50 FTIR from Thermo Fisher Scientific in the mid-IR $\left(4000 \mathrm{~cm}^{-1}-400 \mathrm{~cm}^{-1}\right)$. The diamond crystal was cleaned with ethanol and dried before each measurement. A small amount of sample was pressed directly on the diamond crystal at a pressure of $7 \times 10^{7} \mathrm{~Pa}$. Background and samples were acquired with OMNIC Software at a spectral resolution of $4 \mathrm{~cm}^{-1}$ using 32 scans.

A partial least squares (PLS) method was previously constructed from a series of EVA in order to correlate the composition with the complete IR spectra. 26 EVA samples with well know VAc content were selected as standards to construct the chemometric model. TQ Analyst software from Thermo Fisher Scientific was used for the calibration and for the quantification of the composition of our EVA samples (see ESI $\dagger$ ).

${ }^{1} \mathbf{H}$ and ${ }^{13} \mathbf{C}$ nuclear magnetic resonance (NMR). The analyses were performed on a Bruker Avance III 400 with a BBFO+ $5 \mathrm{~mm}$ probe at $25^{\circ} \mathrm{C}$. The solvent was a mixture of tetrachloroethylene and deuterated benzene at a volume ratio $2 / 1$. The chemical shift scale was calibrated relative to the benzene signal (7.16 ppm).

\section{Results and discussion}

\section{Preliminary comments}

To validate the strategy consisting in using for the first time hydrophilic $\mathrm{P}(\mathrm{AAm}-\mathrm{co}-\mathrm{AA})-\mathrm{X}$ to produce VAE particles, we decided to employ conditions that could be of industrial interest in terms of hydrophilic species content and cost, i.e. using low amount of macroCTA. We thus started by employing $1 \mathrm{wt} \%$ of macroCTA with respect to VAc content and varied the ethylene pressure from 0 to 100 bar. In a second step, and to get a better insight into this system the amount of macroCTA was varied between 1 to $65 \mathrm{wt} \%$. These experiments were all carried out in batch. The switch to semi-batch conditions was the focus of the last part of our study.

Whatever the conditions used in the study, the isolated polymers forming the latexes could not be dissolved in any solvent, which made their analysis by size exclusion chromatography impossible. This phenomenon can find its origins in different reasons. The strong difference in chemical nature between very hydrophilic $\mathrm{P}(\mathrm{AAm}-\mathrm{co}-\mathrm{AA})-\mathrm{X}$ and the hydrophobic formed VAE chains is probably one of them, particularly when the content of macroCTA is high. In addition, the known ability of this copolymerization system to lead to branching ${ }^{1,3,18,52}$ and a possible grafting along the $\mathrm{P}\left(\mathrm{AAm}-\mathrm{co}^{-}\right.$ AA) backbone, ${ }^{1}$ similarly to what was reported with $\mathrm{PVOH}$, may give rise to gel formation impeding complete solubilization. Nevertheless, the formation of translucent gels upon mixing with a mixture of tetrachloroethylene and deuterated benzene still allowed liquid NMR analysis. However, as the signals remained broad, additional characterization tools such as ATR-FTIR, TGA and DSC were used (and detailed in ESI $\dagger$ ) in combination with NMR to determine relevant values for the composition of the formed chains.

\section{Synthesis of poly(vinyl acetate-co-ethylene) latexes under different ethylene pressures using $1 \mathrm{wt} \%$ of macroCTA}

Stable PVAc latex could be formed with $1 \mathrm{wt} \%$ of P(AAm-co-AA)$\mathrm{X}$ after $4 \mathrm{~h}$ of polymerization as shown in Table 1 (entry L1). The $T_{\mathrm{g}}$ measured by DSC is $42.8^{\circ} \mathrm{C}$ (Table 1 and Fig. 2), a bit higher that some literature values for PVAc $\left(e . g ., \sim 30{ }^{\circ} \mathrm{C},{ }^{53}\right.$ $\left.37{ }^{\circ} \mathrm{C},{ }^{9} 41{ }^{\circ} \mathrm{C}^{54}\right)$. Increasing the pressure of ethylene from 10 to 100 bar led to stable latexes too (entries L2 to L5, Table 1), the particle sizes measured by DLS remaining in the same range (145 to $165 \mathrm{~nm}$ ) as the one of the PVAc latex (150 nm) showing the strong ability of $\mathrm{P}(\mathrm{AAm}-\mathrm{co}-\mathrm{AA})-\mathrm{X}$ to stabilize the particles. PdIs remained low $(<0.03)$ and additionally showed that $\mathrm{P}(\mathrm{AAm}-\mathrm{co}-\mathrm{AA})-\mathrm{X}$ induced an efficient nucleation over a broad range of experimental conditions. DLS data were confirmed by cryo-TEM pictures (Fig. 1 for L3, L4 and L5, Table 1). The proof that VAE were formed for the first time using emulsion polymerization of ethylene and vinyl acetate mediated by $\mathrm{P}(\mathrm{AAm}-\mathrm{co}-\mathrm{AA})-\mathrm{X}$ came from DSC measurements of the polymer formed (Fig. 2). Indeed, upon increase of the ethylene pressure, the $T_{\mathrm{g}}$ originally at $42.8^{\circ} \mathrm{C}$ for PVAc, shifted towards lower values (down to $-35.7^{\circ} \mathrm{C}$, L5 in Table 1) as a result of the copolymerization of VAc with ethylene, additionally evidenced by the appearance of a broad crystallization phenomenon when the ethylene pressure is equal or higher than 50 bar (Table 1, $X_{\mathrm{c}}$ ). Indeed, $T_{\mathrm{g}}$ and crystallization phenomena both span a large range of temperatures (see Fig. S4 in ESI $\dagger$ ) and this could depend on different phenomena. While VAc is introduced in the reactor at the beginning of the process, the ethylene pressure is a static pressure that decreases with the consumption of ethylene. Together with the high solubility of VAc in water compared to ethylene, this can induce a strong compositional drift during the copolymerization. ${ }^{14}$ Besides, the conversion of VAc decreases with the increase of the applied pressure and therefore with the incorporation of ethylene $\left(X_{\mathrm{VAc}}=89 \%\right.$ at $10 \mathrm{bar}$ and $61 \%$ at $100 \mathrm{bar}$, Table 1). This is a trend already observed in previous studies. ${ }^{7,55}$ According to Scott et $a .^{7}$ limited VAc conversion would depend upon the composition of the copolymer produced: the higher the ethylene content in the copolymer, the lower the limiting VAc conversion. It is worth noting that the polymer obtained after drying of latex L1 (VAc homopolymerization) was rigid and brittle. As the fraction of ethylene increases in the copolymer, the material isolated after drying becomes more and more flexible, transparent and sticky.

These first successful and promising results show that the production of a broad range of VAE latexes with a very different composition (from $19.1 \mathrm{~mol} \%$ (42 wt\%) to $80.7 \mathrm{~mol} \%$ 

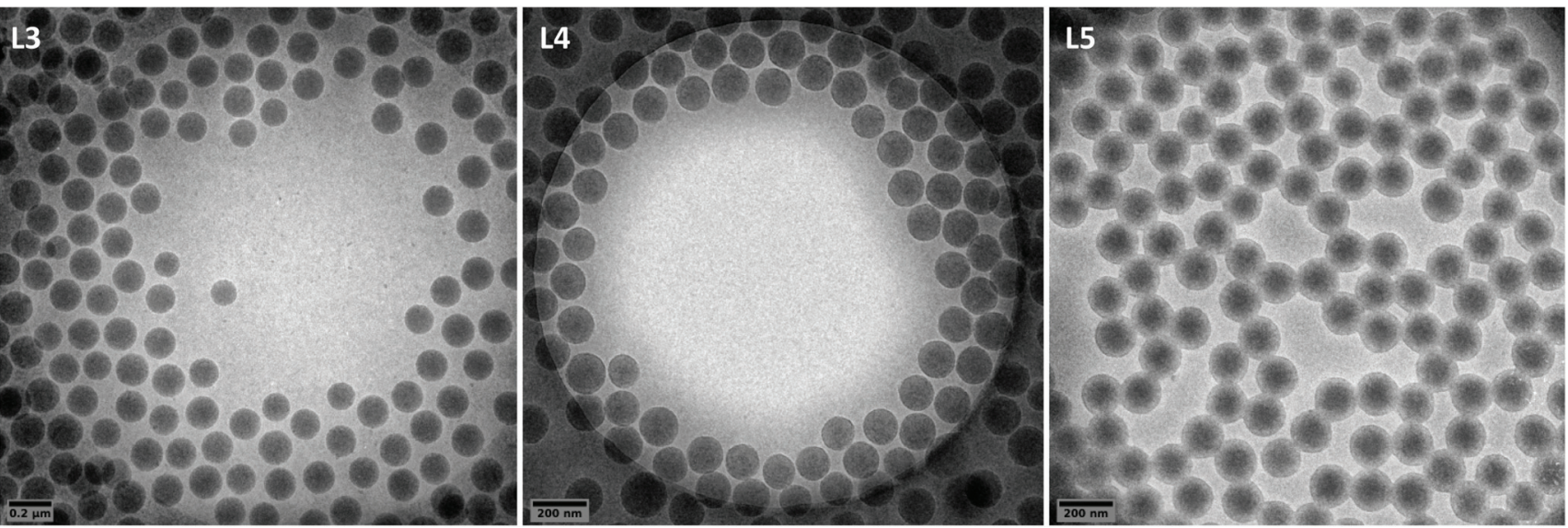

Fig. 1 Cryo-TEM images of P(VAc-CO-E) latexes synthesized with 1 wt\% macroCTA, at different ethylene pressures: 35 bar (L3), 50 bar (L4) and 100 bar (L5).

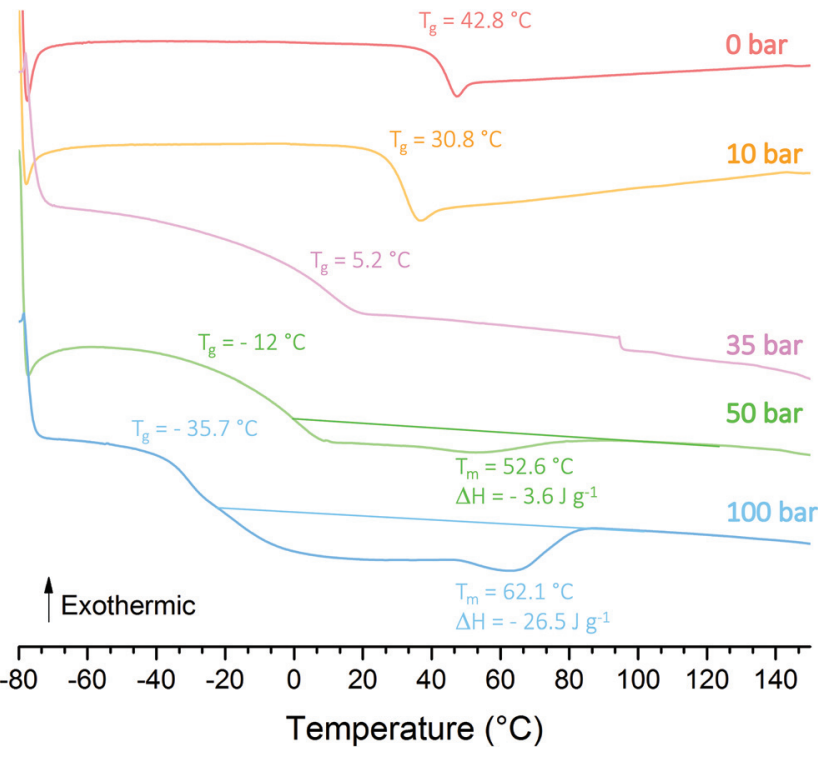

Fig. 2 Thermograms of polymers from experiments L1 (0 bar), L2 (10 bar), L3 (35 bar), L4 (50 bar) and L5 (100 bar) (1 wt\% macroCTA).

(93 wt\%) of VAc) and exhibiting various $T_{\mathrm{g}}$ (from $30.8{ }^{\circ} \mathrm{C}$ to $-35.7^{\circ} \mathrm{C}$ ) was possible using the macroCTA strategy. This strategy is thus a simple way to achieve stable latexes with a minimum amount of macroCTA and to achieve not only VAE but also EVA latexes.

A benchmark experiment further demonstrated the impact of the macroCTA on the particle stabilization. A polymerization was run at 35 bar in absence of macroCTA or any other surfactant (Table 1, L6). A latex was indeed obtained with a SC of $5.8 \mathrm{wt} \%$. However, the particles were significantly larger $(505 \mathrm{~nm})$ and relatively polydisperse $(\mathrm{PdI}=0.1)$. In absence of surfactant, the stability of this latex was only ensured by the charges coming from the initiator and the large particle sizes obtained are consistent with a rather poor efficiency of this stabilization mode. Similarly, large particle sizes were also obtained when the experiment was carried out with $\mathrm{P}(\mathrm{AAm}-\mathrm{co}-$ $\mathrm{AA})$, after removal of the xanthate chain end in $\mathrm{P}(\mathrm{AAm}-\mathrm{co}-\mathrm{AA})$ $\mathrm{X}$, using the same conditions as for latex L3 (L3*, Table 1). The strong reduction in particle size and the obtainment of isometric stable particles for latex L3 $(158 \mathrm{~nm})$ definitively confirms the beneficial implication of the xanthate moieties in the stabilization of the obtained latexes.

Finally, 3 series of experiments were performed using 10 , 20 and 65 wt $\%$ of P(AAm-co-AA)-X (latexes L7 to L20, Table S1, $\dagger$ Fig. 4 and Fig. S1 $\dagger$ ). In all cases, stable latexes were obtained, and systematic characterizations by DSC of the formed polymers allowed to draw for each $\mathrm{P}(\mathrm{AAm}-\mathrm{co}-\mathrm{AA})-\mathrm{X}$ content used, the evolution of $T_{\mathrm{g}}$ versus the ethylene pressure (Fig. 3).

All these experiments demonstrate that a broad range of $\mathrm{P}$ (VAc-co-E) copolymers, from amorphous with tunable $T_{\mathrm{g}}$ to semi-crystalline, can be obtained in the form of stable latexes. As already observed in other studies, ${ }^{9,13}$ the increase of ethylene incorporation in $\mathrm{P}(\mathrm{VAc}-\mathrm{co}$-E) copolymers clearly causes the decrease of $T_{\mathrm{g}}$ (see Fig. S2 $\dagger$ ). This confirms the robustness of this copolymerization system and that the range of potential

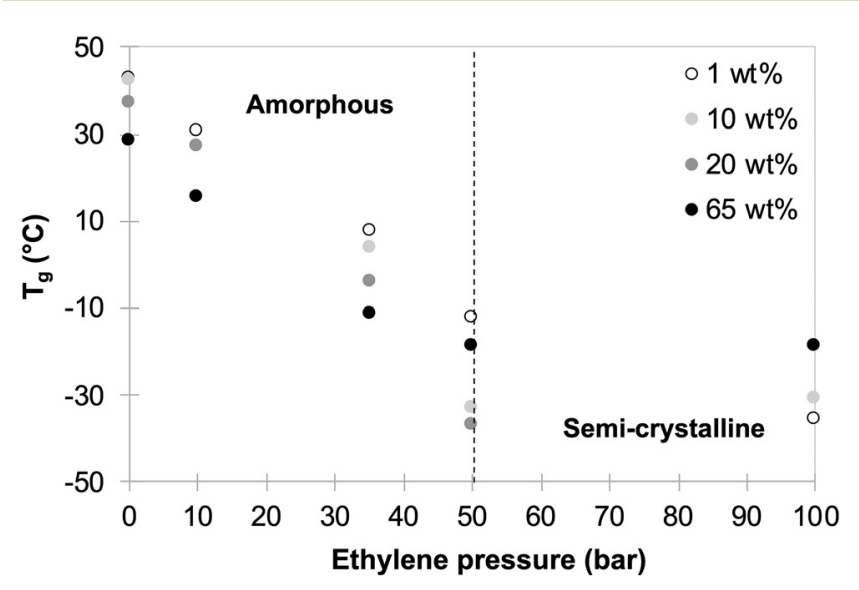

Fig. 3 Variation of $T_{\mathrm{g}}$ as a function of ethylene pressure for different contents of macroCTA ( 1 to $65 \mathrm{wt} \%$ macroCTA/VAc). 
accessible products and polymerization conditions can be expanded even more.

\section{Kinetic studies followed by cryo-TEM}

When varying the macroCTA amount in the aforementioned experiments, the characterizations by cryo-TEM of the different latexes obtained revealed that large and isometric particles ( $c a .150 \mathrm{~nm}$ ) were mainly obtained when the content of $\mathrm{P}(\mathrm{AAm}-\mathrm{co}-\mathrm{AA})-\mathrm{X}$ was $1 \mathrm{wt} \%$ (Fig. 1 ), while a majority of very small particles $(\mathrm{ca} .30 \mathrm{~nm})$ were obtained when its content was increased to $65 \mathrm{wt} \%$ (L19 in Fig. 4 and L18 in Fig. S1†). This trend can be expected when increasing the amount of stabilizer. However, an intermediate regime was observed for 10 and 20 wt $\%$ of $\mathrm{P}(\mathrm{AAm}-\mathrm{co}-\mathrm{AA})-\mathrm{X}$, where bipopulated particles were obtained (Fig. 4), the trend being that the respective fraction of the large particles (ca. $150 \mathrm{~nm}$ ) over the small ones (ca. $30 \mathrm{~nm}$ ) varies according to the $\mathrm{P}(\mathrm{AAm}-\mathrm{co}-\mathrm{AA})-\mathrm{X}$ content, rather independently of the ethylene pressure, the increase of which seems to only slightly increase the size of the large particles.

These results can indeed be explained considering the nucleation mode of the particles. The small particles around $30 \mathrm{~nm}$ are consistent with the formation of micellar aggregates of amphiphilic block copolymers. Those particles would form and be stabilized by the expected mechanism depicted for PISA systems, ${ }^{36}$ in which the growth of the hydrophobic block in water by chain extension of $\mathrm{P}(\mathrm{AAm}-\mathrm{Co}-\mathrm{AA})-\mathrm{X}$ would lead to the self-assembly of the expected $\mathrm{P}(\mathrm{AAm}-c o-\mathrm{AA})-b-\mathrm{P}(\mathrm{VAc}-\mathrm{co}-\mathrm{E})-\mathrm{X}$ block copolymers. Unfortunately, the above-mentioned insolubility of the resulting copolymers did not allow their characterization by SEC analyses. Nevertheless, the very small size of the particles obtained is consistent with the formation and the self-assembly of block copolymers. This results in the shift of the polymerization locus from the aqueous phase to the core of the so-formed block copolymer particles. This nucleation mechanism appears to prevail when the amount of P(AAm-coAA)-X used is high. On the other hand, the large particles may result from particle nucleation induced by much less $\mathrm{P}(\mathrm{AAm}$ $c o$-AA)- $b$-P(VAc-co-E)-X block copolymers as a result of the use of lower amounts of P(AAm-co-AA)-X. P(AAm-co-AA)- $b$-P(VAc- $c o-$ $\mathrm{E})$-X formed would simply act as in situ formed stabilizers for the emulsion copolymerization of ethylene and VAc. In this particular case, the coalescence of the nucleated block copolymer particles to ensure efficient stabilization would lead to larger particles ( $c a .150 \mathrm{~nm}$ ). In addition, conventional emul-


Fig. 4 Cryo-TEM images of P(VAc-Co-E) latexes synthesized at 50 bar of ethylene pressure, using varying amount of macroCTA: 1 wt\% (L4), 10 wt\% (L10), 20 wt\% (L15) and 65 wt\% (L19). Please note that the black dots are related to ice contamination. 
sion copolymerization taking place in the presence of the originally formed small amount of $\mathrm{P}(\mathrm{AAm}-\mathrm{co}-\mathrm{AA})-b-\mathrm{P}(\mathrm{VAc}-\mathrm{co}-\mathrm{E})-\mathrm{X}$ cannot be overruled. It could take place at the same time and also lead to large particles. $\mathrm{P}(\mathrm{AAm}-\mathrm{co}-\mathrm{AA})-\mathrm{X}$ content higher than $1 \mathrm{wt} \%$ and lower than $65 \mathrm{wt} \%$ would then reflect intermediate situations for which both nucleation mechanisms would co-exist.

In order to identify the underpinning nucleation mechanism, we undertook a cryo-TEM kinetic study for the emulsion copolymerization carried under 50 bar of ethylene pressure and using $10 \mathrm{wt} \%$ of $\mathrm{P}(\mathrm{AAm}-\mathrm{co}-\mathrm{AA})-\mathrm{X}$, for which bipopulated latex formed (L10, Fig. 4). As no samples could be withdrawn from the pressurized reactor, the kinetic study is thus the result of 4 similar experiments stopped after 5, 10, 20 and 240 min (latex L21, L22, L23 et L10, Table 1). The polymerization starts between 5 and 10 minutes and is fast before slowing down, as $60 \%$ of the final polymer content $(11.4 \%)$ is reached in 20 minutes.

The cryo-TEM images corresponding to the experiments performed during 10, 20 and $240 \mathrm{~min}$ are presented in Fig. 5. After 10 min of polymerization (L22), small isometric particles of $c a .30 \mathrm{~nm}$ are observed exclusively. This is consistent with the formation of block copolymer aggregates depicted above. A few larger particles (around $100 \mathrm{~nm}$ ) appear between 10 and $20 \mathrm{~min}$ (L23) that keep on growing in size (up to $150 \mathrm{~nm}$ ) and amount, while the size of the small particles remain in the same range $(<40 \mathrm{~nm})$ between 20 and $240 \mathrm{~min}$ (L10). The most likely cause of the formation of these large particles is a phenomenon of coalescence between some micellar aggregates in order to reduce their interfacial area. The coalescence phenomenon will less and less take place when the initial amount of $\mathrm{P}(\mathrm{AAm}-\mathrm{co}-\mathrm{AA})-\mathrm{X}$ is increased, ensuring the stability of all the aggregates.

This kinetic study confirmed the mechanistic picture we provided above for the nucleation of particles formed in our systems. It seems reasonable to assume that the particle nucleation exclusively occurs by self-assembly of block copoly- mers when the content of macroCTA is close to or slightly higher than $10 \mathrm{wt} \%$ (very low fraction of large particles).

\section{Synthesis of poly(vinyl acetate-co-ethylene) latexes using an ethylene pressure of 35 bar and $1 \mathrm{wt} \%$ macroCTA targeting high solids content}

In the last part of the present study, we focused on conditions that could be industrially extrapolated. In that respect, the ethylene pressure was set to 35 bar, pressure commonly used in industry to prepare VAE by emulsion copolymerization. In addition, a particular effort was put on targeting high solids content latexes (>30 wt\%) using a low amount of P(AAm-co$\mathrm{AA})-\mathrm{X}$ that was fixed here to $1 \mathrm{wt} \%$, like in L3. However, this experiment led after 4 hours to solids content of $9.7 \%$ only. A kinetic study was thus performed in order to better comprehend the evolution of the solids content during the polymerization. Again, the kinetic study relied on 4 similar experiments, stopped after 15, 30, 60 and $240 \mathrm{~min}$ (latex L24, L25, L26 et L3, Table 1).

Indeed, the consumption of VAc is very fast $(61 \%$ consumed in $15 \mathrm{~min}$, solids content of $7.4 \%$ ) and seems to be rapidly levelling off at $c a .80 \%$ after $30 \mathrm{~min}$. The decrease of the $T_{\mathrm{g}}$ value observed with time (from $18.5^{\circ} \mathrm{C}$ after $15 \mathrm{~min}$ to $7.7^{\circ} \mathrm{C}$ after $240 \mathrm{~min}$, Table 1) shows that after $30 \mathrm{~min}$, mainly ethylene is polymerized and the solids content does not vary much anymore. This trend, linked to the composition drift, was already observed in the kinetic study above, when using $10 \mathrm{wt} \% \mathrm{P}(\mathrm{AAm}-\mathrm{co}-\mathrm{AA})-\mathrm{X}$ under 50 bar ethylene pressure and in the literature. ${ }^{14}$

The compositional drift is unavoidable when using batch conditions and semi-batch is a way around it $^{7,14}$ (see below). Nevertheless, based on these first observations, the amount of VAc was further varied from $1.09 \mathrm{~mol} \mathrm{~L}^{-1}$ to $4.32 \mathrm{~mol} \mathrm{~L}^{-1}$ to assess its impact on the final solids content. Since the solids content does not vary much after VAc has been consumed, the polymerization time was fixed to $1 \mathrm{~h}$ (L27, L28 and L29, Table 1). The three latexes show solids content of 8.2, 18.6 and
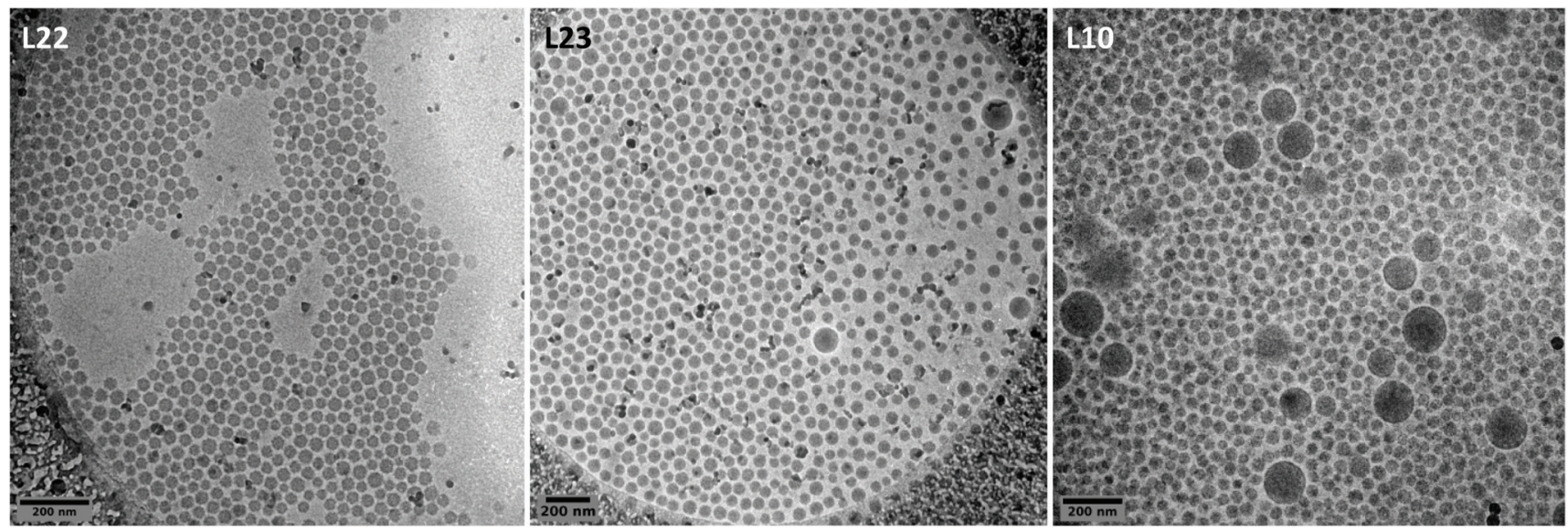

Fig. 5 Cryo-TEM images photos of the latexes obtained during the kinetic study performed at 50 bar with 10 wt\% of macroCTA: $t=10$ min (L22), $t=20 \mathrm{~min}(\mathrm{~L} 23)$ and $t=240 \mathrm{~min}(\mathrm{~L} 10)$. 
$28.8 \mathrm{wt} \%$, respectively, with $T_{\mathrm{g}}$ that are consistent with the formation of VAE (Table 1). L27 and L28 were stable at the end of polymerization and under storage. However, L29 exhibited $15 \%$ coagulum when recovered from the reactor and a strong exotherm $\left(+5.5{ }^{\circ} \mathrm{C}\right)$ was detected in the early stages of the polymerization. As expected, for the stable systems (L27 and L28), VAc was largely consumed ( $87.5 \%$ and $90 \%$, respectively). Eventually, the $T_{\mathrm{g}}$ increase observed (from $11.5{ }^{\circ} \mathrm{C}$ in $\mathrm{L} 26$ to 19.1 ${ }^{\circ} \mathrm{C}$ in L28, Table 1 ) is consistent with an increase of VAc content in the copolymer formed. As a result, the strategy that consists in increasing the amount of VAc in these batch emulsion copolymerizations can produce higher solids content VAE latex. This is however associated with a risk of exotherm potentially leading to the destabilization of the latex, which is redhibitory from an industrial point of view. In addition, as already mentioned, a compositional drift caused by a rapid consumption of VAc in the very beginning of the copolymerization cannot be controlled. For these reasons, a semi-batch process was investigated. In this process, the starting amount of VAc was the one used for L3 (Table 1). The polymerization was started, and the same amount of VAc was added as one shot every hour. The polymerization was stopped 1 hour after the last VAc addition (L30 and L31, with two and three additions of VAc, respectively, Table 2).

Comparison of L28 and L30, for which the same overall amount of VAc was employed, shows the influence of the process (batch vs. semi batch) on the size of the particles (143 nm and $184 \mathrm{~nm}$ for L30 and L28, respectively) and also on the composition of the copolymer ( $T_{\mathrm{g}}$ of 9.9 and $19.1{ }^{\circ} \mathrm{C}$ for L30 and L28, respectively). For a similar final SC (ca. $29.5 \mathrm{wt} \%$ ), more ethylene can be incorporated with the semibatch process.

Encouraged by the previous improvements and in a last attempt to both decrease the amount of the macrocTA employed in the formulation and further increase the solids content, L31 was performed using $0.4 \mathrm{wt} \%$ of $\mathrm{P}(\mathrm{AAm}-\mathrm{co}-\mathrm{AA})-\mathrm{X}$ and 3 additions of VAc, targeting a final VAc content equivalent to $4.32 \mathrm{~mol} \mathrm{~L}^{-1}$ (like in the batch experiment L29). A strong drop of the ethylene pressure was observed, corresponding to almost 17 bar. As already mentioned, the pressure is not maintained at 35 bar over the course of the polymerization. The concentration of ethylene in the reaction medium therefore varies greatly over time, probably here again leading to drifts in compositions. However, again a stable VAE latex was successfully obtained with a final solids content of $38.3 \%$ and a $T_{\mathrm{g}}$ of $14.8{ }^{\circ} \mathrm{C}$ suggesting that with controlled injections of both monomers, this copolymerization system would easily be turned into a powerful tool to produce poly(vinyl acetate-coethylene) copolymers with tunable compositions in emulsion.

\section{Conclusions}

Vinyl acetate/ethylene copolymerization was performed in aqueous emulsion using a $\mathrm{P}(\mathrm{AAm}-\mathrm{co}-\mathrm{AA})$ hydrophilic macro- molecular chain transfer agent prepared by MADIX/RAFT in water.

By varying the macroCTA contents $(1,10,20,65$ wt $\%$ compared to the initial amount of VAC) and the ethylene pressure $(10,35,50,100$ bar), a wide range of $\mathrm{P}(\mathrm{VAc}-\mathrm{co}$-E) latexes (from VAE to EVA) were obtained. In particular, conditions requiring very low amount of hydrophilic $\mathrm{P}(\mathrm{AAm}-\mathrm{co}$-AA)-X macroCTA, i.e. $1 \mathrm{wt} \%$, to produce stable latexes for ethylene pressures spanning from 10 to 100 bar, were identified. Depending on ethylene pressure, copolymers from amorphous to semi-crystalline were obtained. Indeed, the increase in ethylene pressure led to a decrease of the $T_{\mathrm{g}}$ from $42.8^{\circ} \mathrm{C}$ for pure PVAc to $-35.7^{\circ} \mathrm{C}$ at 100 bar. With the help of kinetic studies performed by cryoTEM analyses of the same experiments stopped after different polymerization times, the particle nucleation mechanism was investigated at 50 bar using $10 \mathrm{wt} \%$ of macroCTA. Those conditions indeed led to a final bipopulated latex. Small particles (ca. $30 \mathrm{~nm}$ ) first probably form according to the well-known PISA process leading to very small particles, which then partly coalesce to generate a small fraction of larger particles (ca. $150 \mathrm{~nm}$ ). The fraction of the latter is much less when the macroCTA content employed is higher (20 wt\%) since the system can then accommodate better the stabilization of the created surface area.

With a view to testing conditions more in line with industrial constraints, the final part of the study focused on reaching high solids content for an ethylene pressure of 35 bar, a pressure that is commonly used in the industry to produce VAE latexes. Switching from batch to semi-batch conditions, with successive shot additions of VAc, stable dispersions could be produced with only $0.4 \mathrm{wt} \%$ of macroCTA, and exhibiting a solids content of $38 \mathrm{wt} \%$. To our knowledge, this work is the first study involving RAFT polymerization in the synthesis of poly(vinyl acetate-co-ethylene) in emulsion polymerization. Through the additional use of macroCTA different from $\mathrm{P}(\mathrm{AAm}-\mathrm{co}-\mathrm{AA})$, this work provides an easy access to a full range of alternative stabilization modes for $\mathrm{P}(\mathrm{VAc}-\mathrm{co}-\mathrm{E})$ latexes and potentially to new VAE and EVA products.

\section{Conflicts of interest}

There are no conflicts to declare.

\section{Acknowledgements}

The authors wish to thank Solvay for permission to publish this work.

\section{Notes and references}

1 G. E. J. Reynolds, Br. Polym. J., 1969, 1, 233-238.

2 A. M. Henderson, IEEE Electr. Insul. Mag., 1993, 9, 30-38.

3 P. J. Scott, A. Penlidis and G. L. Rempel, J. Polym. Sci., Part A: Polym. Chem., 1993, 31, 403-426. 
4 J. K. Fink, in Handbook of Engineering and Speciality Thermoplastics: Polyolejns and Styrenics, ed. J. K. Fink, Scrivener Publishing LLC, 2010, pp. 187-209, DOI: 10.1002/ 9780470881712.ch7.

5 A. Zarrouki, E. Espinosa, C. Boisson and V. Monteil, Macromolecules, 2017, 50, 3516-3523.

6 E. Frauendorfer, M. Babar, T. Melchin and W.-D. Hergeth, in Polymer Reaction Engineering of Dispersed Systems: Volume II, ed. W. Pauer, Springer International Publishing, Cham, 2018, pp. 183-214, DOI: 10.1007/12_2017_22.

7 P. J. Scott, A. Penlidis and G. L. Rempel, J. Polym. Sci., Part A: Polym. Chem., 1993, 31, 2205-2230.

8 P. J. Scott, A. Penlidis and G. L. Rempel, Chem. Eng. Sci., 1994, 49, 1573-1583.

9 P. J. Scott, A. Penlidis, G. L. Rempel and A. D. Lawrence, J. Polym. Sci., Part A: Polym. Chem., 1994, 32, 539-555.

10 P. J. Scott, A. Penlidis and G. L. Rempel, Polym. React. Eng., 1995, 3, 93-130.

11 B. A. Gruber, M. S. Vratsanos and C. D. Smith, Macromol. Symp., 2000, 155, 163-170.

12 N. Gospodinova, L. Terlemezyan, M. Mihailov, U. Men Han and K. Ben Du, Eur. Polym. J., 1992, 28, 961-967.

13 N. Gospodinova, T. Zlatkov and L. Terlemezyan, Polymer, 1998, 39, 2583-2588.

14 J. Wu, J. P. Tomba, J. K. Oh, M. A. Winnik, R. Farwaha and J. Rademacher, J. Polym. Sci., Part A: Polym. Chem., 2005, 43, 5581-5596.

15 J. Guo, K. Y. Choi and F. J. Schork, Macromol. React. Eng., 2009, 3, 412-418.

16 F. P. Petrocelli and C. F. Cordeiro, Macromol. Symp., 2000, 155, 39-52.

17 I. Poljanšek, E. Fabjan, K. Burja and D. Kukanja, Prog. Org. Coat., 2013, 76, 1798-1804.

18 N. Gupta, R. K. Srivastava, V. Choudhary, I. K. Varma and S. Patnaik, J. Therm. Anal. Calorim., 1999, 58, 509515.

19 H. S. Mobarakeh and M. R. R. Daronkola, Iran. Polym. J., 2005, 14, 579-587.

20 B. M. Budhlall, K. Landfester, D. Nagy, E. D. Sudol, V. L. Dimonie, D. Sagl, A. Klein and M. S. El-Aasser, Macromol. Symp., 2000, 155, 63-84.

21 B. M. Budhlall, K. Landfester, E. D. Sudol, V. L. Dimonie, A. Klein and M. S. El-Aasser, Macromolecules, 2003, 36, 9477-9484.

22 S. Aruldass, V. Mathivanan, A. R. Mohamed and C. T. Tye, J. Environ. Chem. Eng., 2019, 7, 103238.

23 C. M. Gilmore, G. W. Poehlein and F. J. Schork, J. Appl. Polym. Sci., 1993, 48, 1449-1460.

24 G. S. M. González, V. L. Dimonie, E. D. Sudol, H. J. Yue, A. Klein and M. S. El-Aasser, J. Polym. Sci., Part A: Polym. Chem., 1996, 34, 849-862.

25 B. M. Budhlall, E. D. Sudol, V. L. Dimonie, A. Klein and M. S. El-Aasser, J. Polym. Sci., Part A: Polym. Chem., 2001, 39, 3633-3654.

26 S. Carrà, A. Sliepcevich, A. Canevarolo and S. Carrà, Polymer, 2005, 46, 1379-1384.
27 A. L. German and D. Heikens, J. Polym. Sci., Part A-1: Polym. Chem., 1971, 9, 2225-2232.

28 A. L. German and D. Heikens, Anal. Chem., 1971, 43, 19401944.

29 M. Rätzsch, W. Schneider and D. Musche, J. Polym. Sci., Part A-1: Polym. Chem., 1971, 9, 785-790.

30 R. Van Der Meer, M. W. A. M. Aarts and A. L. German, J. Polym. Sci., Polym. Chem. Ed., 1980, 18, 1347-1357.

31 J. Filley, J. T. McKinnon, D. T. Wu and G. H. Ko, Macromolecules, 2002, 35, 3731-3738.

32 H. De Bruyn, R. G. Gilbert and B. S. Hawkett, Polymer, 2000, 41, 8633-8639.

33 E. J. Bradbury, D. McNulty, R. I. Savage and E. E. McSweeney, Ind. Eng. Chem., 1952, 44, 211-212.

34 P. B. Zetterlund, S. C. Thickett, S. Perrier, E. Bourgeat-Lami and M. Lansalot, Chem. Rev., 2015, 115, 9745-9800.

35 J. Zhou, H. Yao and J. Ma, Polym. Chem., 2018, 9, 25322561.

36 F. D'Agosto, J. Rieger and M. Lansalot, Angew. Chem., 2020, 59, 8368-8392.

37 N. J. W. Penfold, J. Yeow, C. Boyer and S. P. Armes, ACS Macro Lett., 2019, 8, 1029-1054.

38 J. L. de la Haye, I. Martin-Fabiani, M. Schulz, J. L. Keddie, F. D'Agosto and M. Lansalot, Macromolecules, 2017, 50, 9315-9328.

39 I. Martín-Fabiani, J. L. de la Haye, M. Schulz, Y. Liu, M. Lee, B. Duffy, F. D'Agosto, M. Lansalot and J. L. Keddie, ACS Appl. Mater. Interfaces, 2018, 10, 11221-11232.

40 I. Martín-Fabiani, D. K. Makepeace, P. G. Richardson, J. L. de la Haye, D. A. Venero, S. E. Rogers, F. D'Agosto, M. Lansalot and J. L. Keddie, Langmuir, 2019, 35, 38223831.

41 V. Dehan, E. Bourgeat-Lami, F. D'Agosto, B. Duffy, A. Fortini, S. Hilton, K. Krassa, J. L. Keddie, M. L. Koh, M. Lansalot, M. Lee, J. L. de la Haye, I. Martin-Fabiani, C. Mantzaridis, D. P. Mazeffa, R. P. Sear, M. Schulz, M. Sibbald, B. Skerry and B. Thomas, Steel Constr., 2017, 10, 254-259.

42 A. France, WO2019063445, 2019.

43 Solvay SA, Centre National de la Recherche Scientifique, Université Pierre et Marie Curie (Paris 6), Université Claude Bernard Lyon 1, WO2013092587A1, 2013.

44 E. Velasquez, J. Rieger, F. Stoffelbach, B. Charleux, F. D'Agosto, M. Lansalot, P.-E. Dufils and J. Vinas, Polymer, 2013, 54, 6547-6554.

45 E. Velasquez, J. Rieger, F. Stoffelbach, F. D’Agosto, M. Lansalot, P.-E. Dufils and J. Vinas, Polymer, 2016, 106, 275-284.

46 E. Grau, P.-Y. Dugas, J.-P. Broyer, C. Boisson, R. Spitz and V. Monteil, Angew. Chem., Int. Ed., 2010, 49, 6810-6812.

47 F. Brunel, G. Billuart, P.-Y. Dugas, M. Lansalot, E. BourgeatLami and V. Monteil, Macromolecules, 2017, 50, 9742-9749.

48 G. Billuart, E. Bourgeat-Lami, M. Lansalot and V. Monteil, Macromolecules, 2014, 47, 6591-6600.

49 S. Binauld, L. Delafresnaye, B. Charleux, F. D’Agosto and M. Lansalot, Macromolecules, 2014, 47, 3461-3472. 
50 P. Galanopoulo, P.-Y. Dugas, M. Lansalot and F. D'Agosto, Polym. Chem., 2020, 11, 3922-3930.

51 C. Bergerbit, F. Baffie, A. Wolpers, P.-Y. Dugas, O. Boyron, M. Taam, M. Lansalot, V. Monteil and F. D’Agosto, Angew. Chem., 2020, 59, 10385-10390.

52 M. J. Wisotsky, A. E. Kober and I. A. Zlochower, J. Appl. Polym. Sci., 1971, 15, 1737-1742.
53 C. F. Cordeiro and F. P. Petrocelli, in Kirk-Othmer Encyclopedia of Chemical Technology, 2005, DOI: 10.1002/ 0471238961.2209142503151804.a01.pub2.

54 A. C. Mesquita, M. N. Mori and L. G. Andrade e Silva, Radiat. Phys. Chem., 2004, 71, 253-256.

55 G. Billuart, Free radical emulsion polymerization of ethylene, Université Claude Bernard Lyon 1, 2015. 